\title{
Zirconia-supported niobia catalyzed formation of propanol from 1,2-propanediol via dehydration and consecutive hydrogen transfer
}

\author{
Gongming Peng, Xicheng Wang, Xiufang Chen, Yijun Jiang, Xindong $\mathrm{Mu}^{*}$ \\ Key Laboratory of Biobased Materials, Qingdao Institute of Bioenergy and Bioprocess Technology, Chinese Academy of Sciences, Qingdao 266101, PR China
}

\section{A R T I C L E I N F O}

\section{Article history:}

Received 4 July 2013

Accepted 10 November 2013

Available online 16 November 2013

\section{Keywords:}

Zirconia-supported niobia

1,2-Propanediol

Hydrogen transfer

\begin{abstract}
A B S T R A C T
Vapor-phase catalytic dehydration of 1,2-propanediol was investigated over Zirconia-supported niobia catalysts. The catalysts exhibit selectivity favoring propanol (approximately 39\%) at $85.0 \% 1,2-$ propanediol conversion at $290{ }^{\circ} \mathrm{C}$ under $1 \mathrm{~atm} \mathrm{~N}$. The $\mathrm{ZrNbO}$ catalysts were analyzed by various techniques; the results indicated that the active sites were weak Brønsted acid sites. A dehydration and hydrogen transfer mechanism was also proposed.
\end{abstract}

(c) 2013 The Korean Society of Industrial and Engineering Chemistry. Published by Elsevier B.V. All rights reserved.

\section{Introduction}

Large amounts of glycerol are currently generated as a byproduct in biodiesel manufacture by transesterification of seed oils [1]. The global production for refined glycerol has increased over the last few years at an average annual rate of $8.7 \%$, and this increased supply has subsequently resulted in a sharp decrease in the price of this product [2]. Consequently, it is highly desirable to convert low-cost glycerol into value-added chemicals or materials. Toward this end, many research groups study transforming glycerol into value-added chemicals, such as dihydroxyacetone [3-5], acrolein [6,7], 1,2-propanediol (1,2-PDO), 1,3-propanediol (1,3-PDO) [8-11], and biopropanols, by catalytic processes.

Among the products, 1-propanol is also a high value commodity chemical, which is used mainly as a solvent, a component of printing ink and a chemical intermediate for the production of $n$ propyl acetate [12]. There are various strategies for the production of 1-propanol from glycerol or glycerol-derived PDO. One process used to access this compound involve the conversion of glycerol to biopropanols on using variety of catalysts $[2,13]$. Another welldeveloped procedure accesses biopropanols via glycerol-derived propanediols. So far, glycerol hydrogenolysis has been extensively studied. It has been known that the glycerol hydrogenolysis to 1,2PDO is more selective than that to 1,3-PDO [14-17]. As a result, 1,2PDO is more preferable as a substrate for the production of 1propanol. On the other hand, there have been several works on the catalyst development for the glycerol hydrogenolysis to 1,3-PDO

\footnotetext{
* Corresponding author. Tel.: +86 352 80662723; fax: +86 35280662724 .

E-mail address: Muxd@qibebt.ac.cn (X. Mu).
}

like Rh-ReOx [18], Ir-ReOx [19], and Pt-WOx [20] and so on. Commonly, these catalysts showed the selective hydrogenolysis of 1,2-propanediol to 1-propanol (selectivity is beyond $80 \%$ ) and that of 1,3-propanediol to 1-propanol [21]. Totally, the catalysts for the selective hydrogenolysis of glycerol to 1,3-propanediol have a potential in the production of 1-propanol from glycerol. However, these systems need high pressure hydrogen and Rh-based or Ptbased catalysts, which are expensive.

Achieving low cost and mild reaction conditions are the prime interests for this reaction. Zhang et al. [22] found zeolites can catalyze $1,2-\mathrm{PDO}$ into 1 -propanol at $250-300{ }^{\circ} \mathrm{C}$ at ambient pressure under nitrogen. However, as a by-product, the yield of 1 -propanol was only $21.2 \%$. Therefore, how to improve the 1 propanol yield from 1,2-PDO with a non-noble metal catalyst without using hydrogen is an interesting and challenging work.

Herein, we report the development of a $\mathrm{ZrNbO}$ catalyst; the use of this catalyst results in a $33.0 \%$ yield of 1 -propanol at $85.0 \%$ conversion of 1,2-PDO under $1 \mathrm{~atm} \mathrm{~N}_{2}$. To the best of our knowledge, this is the highest yield of 1-propanol achieved under an inert atmosphere at ambient pressure. Notably, 1-propanol was formed as the main product, with acetol and propanal as additional products, even though no molecular hydrogen or additional hydrogen donor, such as 2-propanol [23] or formic acid, [24] was present in the system.

\section{Experimental}

\subsection{Catalyst preparation}

$\mathrm{ZrO}_{2}\left(S_{\mathrm{BET}}=168 \mathrm{~m}^{2} \mathrm{~g}^{-1}\right)$ was prepared by the hydrolysis of zirconium chloride as reported by G.K. Chuah et al. [25]. $\gamma-\mathrm{Al}_{2} \mathrm{O}_{3}$ 
Table 1

Physico-chemical properties of the catalysts.

\begin{tabular}{|c|c|c|c|c|}
\hline Catalyst & $\mathrm{Nb}(\%)$ & $\mathrm{Nb}_{2} \mathrm{O}_{5}(\%)$ & $S_{\mathrm{BET}}\left(\mathrm{m}^{2} \mathrm{~g}^{-1}\right)$ & $\mathrm{Nb}$ Surface density $\left(\mathrm{Nb} \mathrm{nm}^{-2}\right)$ \\
\hline $\mathrm{ZrO}_{2}$ & - & - & 168 & - \\
\hline ZrNbO-0.7 & 1.6 & 2.37 & 153 & 0.7 \\
\hline ZrNbO-1.2 & 2.6 & 3.84 & 143 & 1.2 \\
\hline ZrNbO-2.0 & 4 & 5.94 & 131 & 2.0 \\
\hline
\end{tabular}

(Chinalco, $S_{\mathrm{BET}}=500 \mathrm{~m}^{2} \mathrm{~g}^{-1}$ ), and $\mathrm{TiO}_{2} \quad(\mathrm{P}-25, \quad$ Degussa, $S_{\mathrm{BET}}=55 \mathrm{~m}^{2} \mathrm{~g}^{-1}$ ) were also tested for comparison.

$30 \% \mathrm{HSiW} / \mathrm{SiO}_{2}$ was prepared by an impregnation method, according to the literature [26]. $15 \% \mathrm{WOx} / \mathrm{ZrO}_{2}$ was prepared by impregnation of zirconium oxyhydroxide solids with ammonium metatungstate solutions [27]. $15 \% \mathrm{WOx} / \mathrm{Al}_{2} \mathrm{O}_{3}$ and $15 \% \mathrm{WOx} / \mathrm{TiO}_{2}$ were prepared by incipient wetness impregnation using ammonium metatungstate as the precursor. $5 \% \mathrm{NbOx} / \mathrm{Al}_{2} \mathrm{O}_{3}$ and $5 \% \mathrm{NbOx} /$ $\mathrm{TiO}_{2}$ were prepared by incipient wetness impregnation using ammonium oxalate-niobate as the precursor. All of above solution except $\mathrm{HSiW} / \mathrm{SiO}_{2}$ dried over night at $110{ }^{\circ} \mathrm{C}$ before grinding and calcination at $600{ }^{\circ} \mathrm{C}$ for $2 \mathrm{~h}$.

ZrNbO catalyst was prepared by impregnation. The impregnation was conducted in acidified water with ammonium oxalatoniobate [6]. The samples obtained were denoted as ZrNbO- $x$, with $x$ the $\mathrm{Nb}$ Surface density. It should be noted that support here is different from that in the work of P. Lauriol-Garbey et al. [6]. The support corresponds to a mixture of tetragonal and monoclinic phases with a specific surface area of $168 \mathrm{~m}^{2} \mathrm{~g}^{-1}$ (Table 1 ).

\subsection{Catalyst characterization}

The X-ray powder diffraction (XRD) patterns of catalyst samples were obtained with a Bruker D8 Advance X-ray diffraction meter under $\mathrm{Ni}$-filtered $\mathrm{Cu}-\mathrm{K} \alpha$ radiation. BET surface area was measured by nitrogen adsorption on a Micromeritics ASAP 2020 surface area and porosity analyzer. $\mathrm{NH}_{3}$-TPD and $\mathrm{CO}_{2}$-TPD experiments were performed with a Micromeritics Autochem II chemisorption analyzer. In situ diffuse reflectance infrared Fourier transform spectroscopy (DRIFTS) spectra were recorded with a Nicolet 710 FT-IR spectrometer.

\subsection{Catalytic test}

The conversion of 1,2-PDO to 1-propanol was performed in a fixed-bed reactor ( $8 \mathrm{~mm}$ i.d.). In a typical reaction, $1 \mathrm{~g}$ of catalyst was mixed with a known amount of quartz sand and put into the tube reactor. After the temperature of the reactor had reached $290{ }^{\circ} \mathrm{C}$, a $30 \mathrm{wt} . \% 1,2-\mathrm{PDO}$ aqueous solution was pumped into the reactor at a flow rate of $1.8 \mathrm{~mL} \mathrm{~h}^{-1}$ using a syringe pump (SSI Series II Pump). Nitrogen, at a flow rate of $30 \mathrm{~mL} \mathrm{~min}^{-1}$, was used as carrier gas. The products were collected hourly in ethanol cooled by an ice-water trap. The products in the resultant solutions were identified by data collected from gas chromatograph (GC, 7890A, Agilent, USA) coupled with a mass spectrometer (MS, 5975C, Agilent, USA) after the reaction was complete.

\section{Results and discussion}

The performance of different catalysts with respect to $1,2-$ propanediol conversion was tested, and the results were shown in Table 2. Over $\mathrm{ZrO}_{2}$, 1,2-propanediol was transformed mainly to acetol via dehydrogenation with $22.9 \%$ selectivity, propanal and acetone via dehydration and, finally, only 19.8\% 1-propanol was detected (Table 2, entry 1 ). Over $\mathrm{Al}_{2} \mathrm{O}_{3}$, the selectivity for 1 propanol was only $17.4 \%$ (Table 2 , entry 2 ) and $11.2 \%$ selectivity for 1-propanol over $\mathrm{TiO}_{2}$ (Table 2, entry 3) was observed. However, the overall conversion of 1,2-propanediol was still low over these catalysts.

When using strongly Brønsted acidic $30 \% \mathrm{HSiW} / \mathrm{SiO}_{2}$, propanal was produced with a selectivity of $86.0 \%$ via pinacol rearrangement [28] (Table 2, entry 5). $\mathrm{Nb}_{2} \mathrm{O}_{5}$, which is strongly Lewis acidic (Aladdin, 99.95\%), produced products in lower selectivity with

Table 2

Results of 1,2-propanediol conversion over various catalysts ${ }^{\mathrm{a}}$.

\begin{tabular}{|c|c|c|c|c|c|c|c|c|}
\hline \multirow[t]{2}{*}{ Entry } & \multirow[t]{2}{*}{ Catalyst } & \multirow[t]{2}{*}{ Conversion (\%) } & \multirow[t]{2}{*}{ Yield $^{\mathrm{b}}(\%)$} & \multicolumn{5}{|l|}{$\mathrm{S}_{\mathrm{i}}^{\mathrm{c}}(\%)$} \\
\hline & & & & Propanol & Propanal & Dioxolane & Acetol & Acetone \\
\hline 1 & $\mathrm{ZrO}_{2}$ & 53.7 & 10.6 & 19.8 & 17.9 & - & 22.9 & 2.4 \\
\hline 2 & $\gamma-\mathrm{Al}_{2} \mathrm{O}_{3}$ & 36.3 & 6.3 & 17.4 & 18.6 & 6.7 & 33.4 & 3.5 \\
\hline 3 & $\mathrm{TiO}_{2}$ & 32.9 & 3.7 & 11.2 & 26.2 & 0.4 & 13.5 & 11.6 \\
\hline 4 & $\mathrm{Nb}_{2} \mathrm{O}_{5}$ & 94.8 & 9.2 & 9.7 & 51.2 & 5.1 & 3.3 & 12.7 \\
\hline 5 & $30 \% \mathrm{HSiW} / \mathrm{SiO}^{\mathrm{d}}$ & 96.9 & 1.2 & 1.2 & 86.0 & 3.2 & - & 5.0 \\
\hline 6 & $\mathrm{WO}_{x} / \mathrm{ZrO}_{2}$ & 86.4 & 13.9 & 16.1 & 54.3 & 4.1 & 10.3 & 1.0 \\
\hline 7 & $\mathrm{WO}_{x} / \mathrm{Al}_{2} \mathrm{O}_{3}$ & 81.9 & 11.7 & 14.3 & 63.6 & - & 2.9 & 1.8 \\
\hline 8 & $\mathrm{WO}_{x} / \mathrm{TiO}_{2}$ & 82.0 & 2.0 & 2.8 & 66.6 & 1.0 & 4.1 & 10.4 \\
\hline 9 & $\mathrm{NbO}_{x} / \mathrm{Al}_{2} \mathrm{O}_{3}$ & 85.1 & 9.8 & 11.5 & 44.2 & 3.3 & 11.5 & 4.9 \\
\hline 10 & $\mathrm{NbO}_{x} / \mathrm{TiO}_{2}$ & 74.5 & 6.8 & 9.1 & 33.4 & 0.5 & 6.4 & 8.6 \\
\hline 11 & ZrNbO-0.7 & 70.9 & 19.1 & 27.0 & 25.0 & - & 15.1 & 3.6 \\
\hline 12 & ZrNbO-1.2 & 85.0 & 33.1 & 39.0 & 27.4 & 1.0 & 21.8 & 4.7 \\
\hline 13 & ZrNbO-2.0 & 86.1 & 26.2 & 30.5 & 29.7 & - & 18.9 & 9.5 \\
\hline 14 & Ferrierite $(20)^{\mathrm{e}}$ & 83.2 & 21.2 & 25.5 & 29.1 & 39.1 & - & 1.2 \\
\hline
\end{tabular}

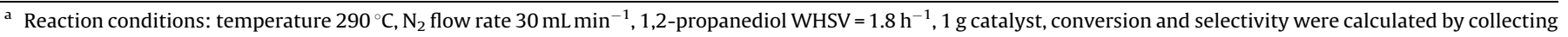
the effluent produced between initial 1 and $8 \mathrm{~h}$.

b Yield of propanol.

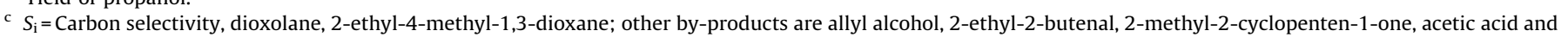
several unknown products.

d $T=210^{\circ} \mathrm{C}$.

e Reference [12] 


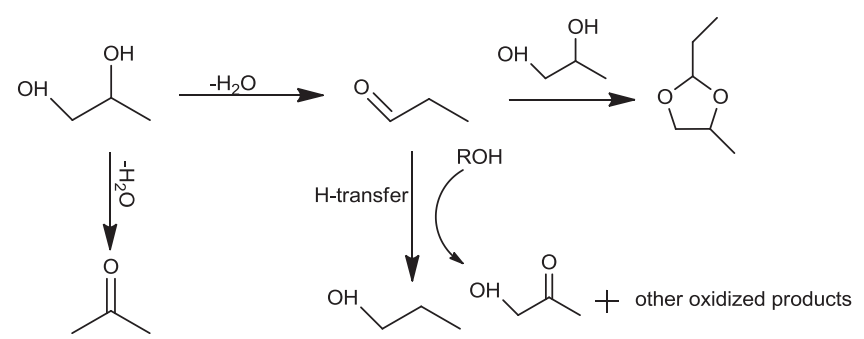

Scheme 1. Reaction pathways from 1,2-propanediol to propanol.

respect to propanal (51.2\%, Table 2, entry 4). A series of supported tungsten oxide catalysts, with strong, medium strong and weak acid sites [29], produced propanal as the principal product and some 1-propanol could also be detected over $\mathrm{WO}_{x} / \mathrm{ZrO}_{2}$ and $\mathrm{WO}_{x} \mid$ $\mathrm{Al}_{2} \mathrm{O}_{3}$, but not $\mathrm{WO}_{x} / \mathrm{TiO}_{2}$ (Table 2, entries 6-8). $\mathrm{NbO}_{x} / \gamma-\mathrm{Al}_{2} \mathrm{O}_{3}$ produced more propanal, with a selectivity of $44.2 \%$, than $\mathrm{NbO}_{x} /$ $\mathrm{TiO}_{2}(33.4 \%$ ) (Table 2, entries 9, 10), but the yield of the desired 1propanol was still relatively low ( $<10 \%)$. Unexpectedly, $\mathrm{ZrNbO}$ catalysts gave a remarkable increase in the yield of 1-propanol (Table 2, 11-13). The yield of 1-propanol was dramatically improved when the content of $\mathrm{Nb}$ was increased to 1.2 atom $\mathrm{nm}^{-2}$. 2. ZrNbO-1.2 showed the highest 1-propanol yield of $33.1 \%$, however, further increase of $\mathrm{Nb}$ density led to the decrease of 1 propanol yield.

Zhang et al. [22] proposed that both the formation of 1propanol and the formation of dioxolane were linked to the same properties of catalyst. Bergman et al. recently reported the preparation of allyl alcohol via a formic acid-mediated deoxygenation of glycerol [24]. Obviously, our catalytic results cannot be explained based solely on the above results because very little dioxolane was found and no formic acid was present in our experiments. Schüth et al. inferred that glycerol was converted to allyl alcohol through dehydration and consecutive hydrogen

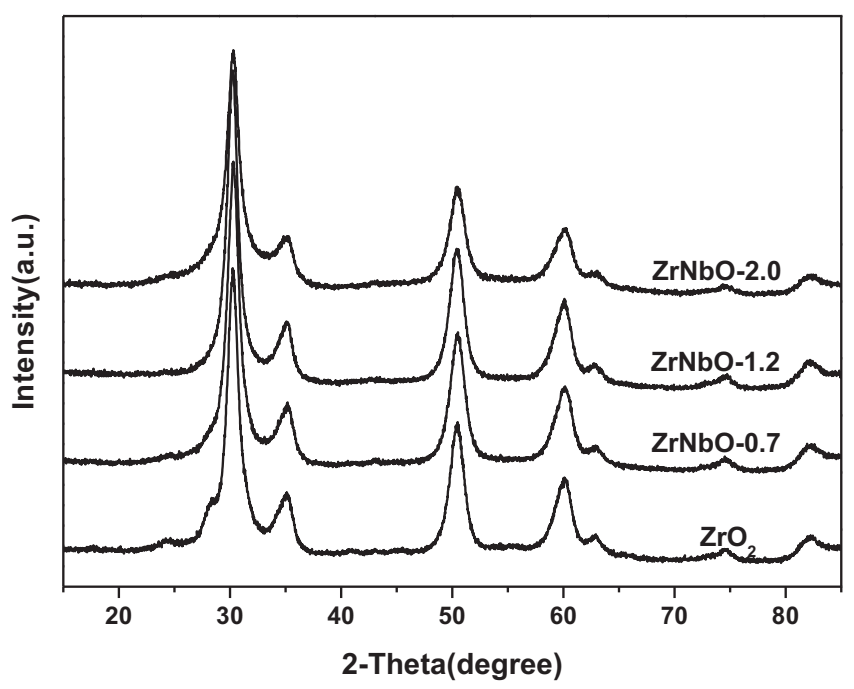

Fig. 1. Powder X-ray diffraction patterns of the catalysts.

transfer [30]. This explanation better suits our system and the probable reaction pathway is shown in Scheme 1.

Acetone and propanal are both products of the 1,2-propanediol dehydration reaction and dioxolane is produced from the reaction between the 1,2-propanediol and propanal. 1-Propanol may be obtained through a hydrogen transfer reaction with an alcohol acting as the hydrogen donor. It is worth noting that selectivity for acetol was lower than that of 1-propanol, indicating that 1,2propanediol may not be the only the hydrogen donor for the hydrogen transfer reaction. According to previous literature reports [30], some intermediates with hydroxyl groups were formed during reaction, resulting in a mixture of these products

Table 3

Yields of hydrogen transfer reactions between propanal and different alcohols catalyzed by ZrNbO catalysts ${ }^{\mathrm{a}}$.

\begin{tabular}{|c|c|c|c|c|c|c|c|}
\hline Entry & Substrate & $\mathrm{H}$ - donor & Product & Conv $^{\mathrm{b}}(\%)$ & $\operatorname{Conv}^{\mathrm{c}}(\%)$ & Yield $^{\mathrm{d}}(\%)$ & $\mathrm{S}^{\mathrm{e}}(\%)$ \\
\hline 1 & & & $\mathrm{HO}$ & 85.0 & 87.5 & 2.7 & 3.2 \\
\hline 2 & & & $\mathrm{HO}$ & 88.2 & 84.3 & 3.2 & 3.6 \\
\hline 3 & & & $\mathrm{HO}$ & 93.3 & 85.3 & 4.3 & 4.8 \\
\hline 4 & & & $\mathrm{HO}$ & 87.5 & 77.8 & 4.8 & 5.5 \\
\hline 5 & & & $\mathrm{HO}$ & 92.4 & 90.5 & 1.4 & 1.5 \\
\hline 6 & & & $\mathrm{HO}$ & 85.6 & 82.1 & 3.9 & 4.6 \\
\hline $7^{f}$ & & & $\mathrm{HO}$ & 94.5 & 86.4 & 15.7 & 16.7 \\
\hline
\end{tabular}

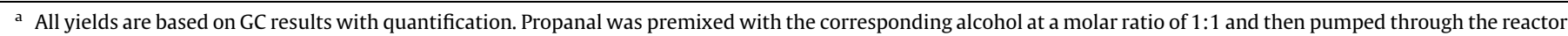
at the same temperature, catalyst amount, and flow rate.

$b$ The conversion of substrate.

c The conversion of H-donor.

d The yield of products based on substrate.

e Selectivity of 1-propanol.

f 1,2-propanediol: propanal molar ratio $=2: 1$, propanol yield was calculated based on the amount of 1,2-propanediol. 


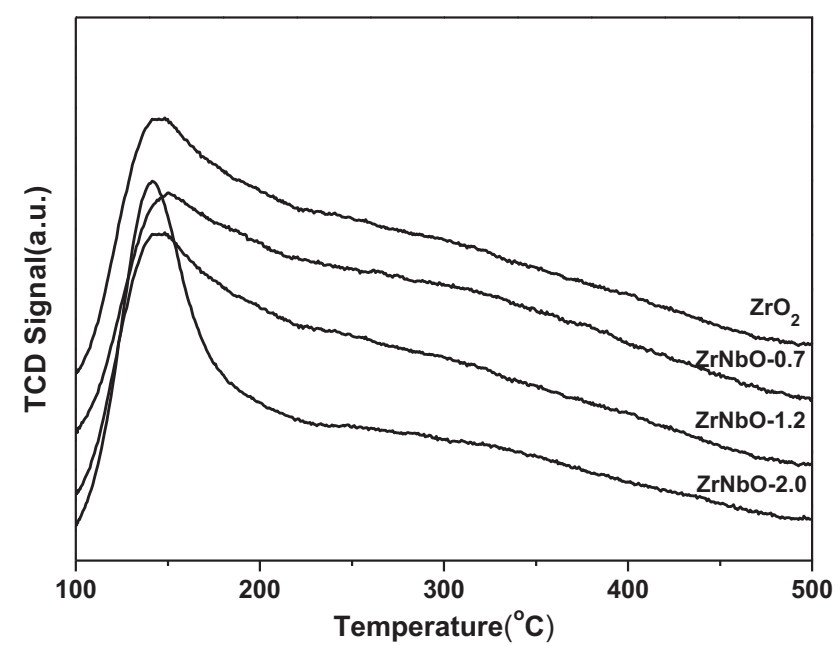

Fig. 2. $\mathrm{NH}_{3}-\mathrm{TPD}$ profiles of the $\mathrm{ZrNbO}$ catalyst species.

with 1,2-propanediol; any of these compounds could then serve as the hydrogen donor.

To better understand the mechanism, several reactions between different alcohols and propanal were performed, and the results are shown in Table 3. It can be seen that hydrogen transfer reactions can indeed take place with a variety of alcohols,

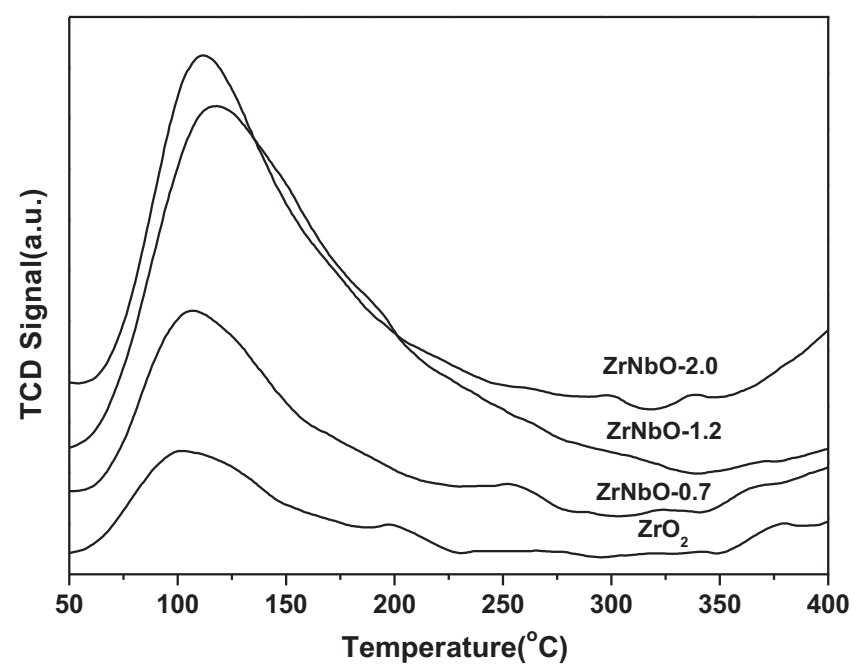

Fig. 3. $\mathrm{CO}_{2}-\mathrm{TPD}$ profiles of the $\mathrm{ZrNbO}$ catalyst species.

although the yields of the 1-propanol are considerably lower than for the ZrNbO-1,2-propanediol system. These results confirmed that the hydrogen transfer does not only include the reaction between 1,2-propanediol and propanal.

To understand the origin of the observed catalytic properties, studies on the structure and surface formation of $\mathrm{ZrNbO}$ catalyst

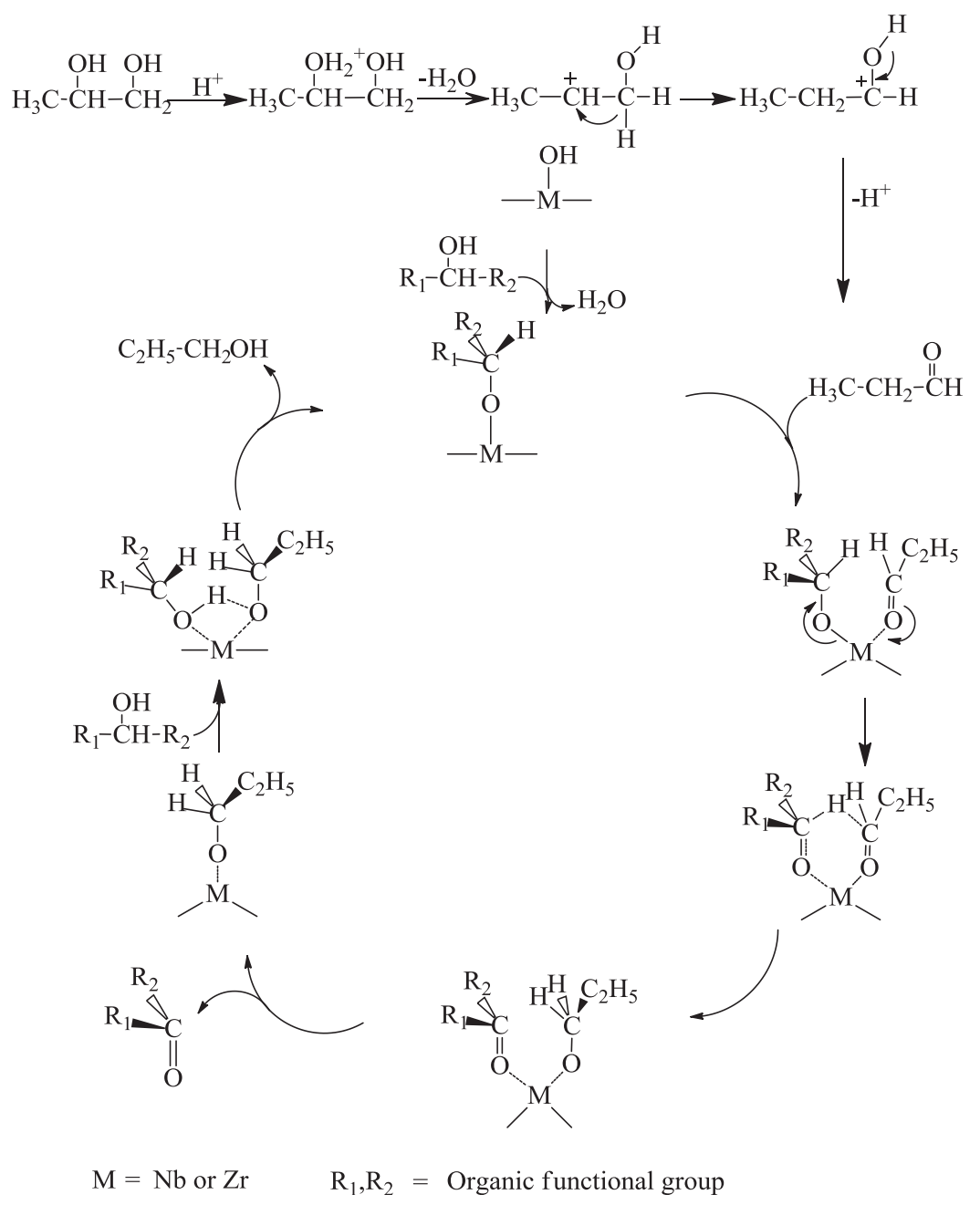

Scheme 2. Possible mechanism of 1,2-propanediol converted to propanol over ZrNbO catalysts. 


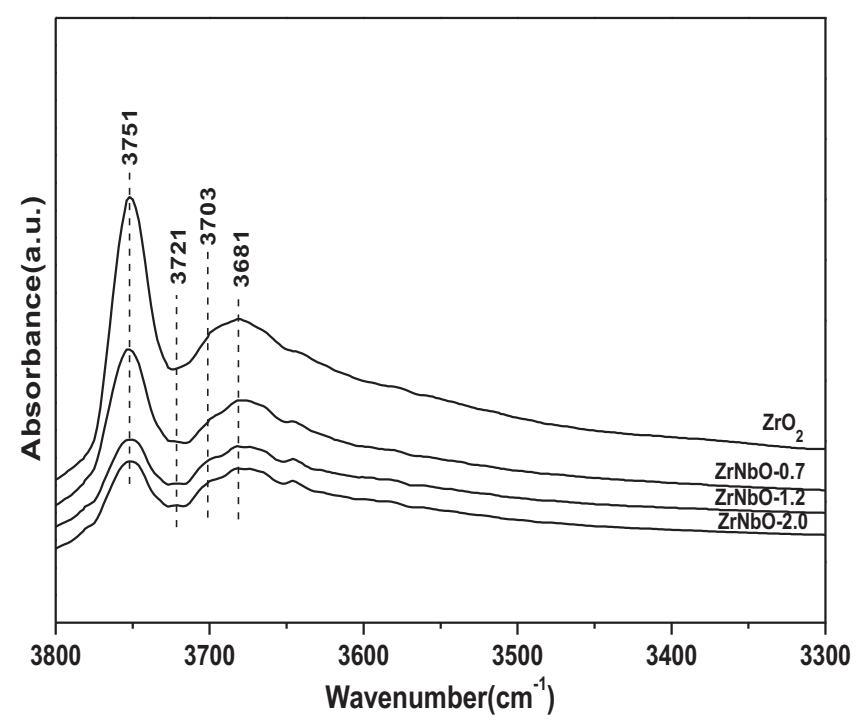

Fig. 4. In situ DRIFTS spectra of the hydroxyl region of supported niobia catalysts.

samples were conducted. The X-ray diffraction pattern of $\mathrm{ZrO} 2$ revealed two phase, which corresponed to tetragonal zirconia ( $t$ $\mathrm{ZrO} 2$ ) and monoclinic zirconia ( $\mathrm{m}-\mathrm{ZrO} 2)$ (Fig. 1).The relative $\mathrm{m}$ $\mathrm{ZrO} 2$ phase disappeared when niobium was incorporated into $\mathrm{ZrO} 2$. It means that niobium helps in the stabilization of the tetragonal form [6] (Fig. 1). The TPD of $\mathrm{NH}_{3}$ and $\mathrm{CO}_{2}$ were also measured to investigate the surface acid-base properties of the catalysts. Fig. 2 showed $\mathrm{NH}_{3}$-TPD profiles of the $\mathrm{ZrNbO}$ samples. All of the thermograms have two broad maxima: the first of these was found at approximately $150{ }^{\circ} \mathrm{C}$, and the second occurred in the range between 300 and $400{ }^{\circ} \mathrm{C}$. For the $\mathrm{ZrNbO}$ samples, the density of the weak acid sites increased with increasing the $\mathrm{Nb}$ content while the density of the strong acid sites decreased accordingly. Fig. 3 shows TPD profiles of $\mathrm{CO}_{2}$ adsorbed on ZrNbO catalysts. $\mathrm{CO}_{2}$ was desorbed in a wide temperature range. The peak intensities in TPD profiles of $\mathrm{CO}_{2}$ increased gradually as the $\mathrm{Nb}$ content increased. This indicated that $\mathrm{ZrO}_{2}$ had weak basicity and the surface basicity were enhanced by the addition of Nb. Fig. 4 shows in situ DRIFTS spectroscopy results for different samples. The hydroxyl region of zirconia displayed two bands at 3681 and $3751 \mathrm{~cm}^{-1}$, which have been assigned to surface hydroxyl groups bonded to three and one $\mathrm{Zr}$ atoms, respectively [31]. The larger decrease in intensity of the band at $3751 \mathrm{~cm}^{-1}$ indicated that hydroxyl groups bound to a single $\mathrm{Zr}$ atom were more reactive toward deposited niobia [31]. The new band at $3721 \mathrm{~cm}^{-1}$ and the shoulder at $3703 \mathrm{~cm}^{-1}$, for both of which the assignments were unknown, may be due to isolated $\mathrm{Nb}-\mathrm{OH}$ hydroxyl groups or $\mathrm{Nb}-$ $\mathrm{OH}-\mathrm{Zr}$ bridging hydroxyl groups [32].

In the ZrNbO catalysts, Brønsted acid sites are the active sites for the dehydration reaction $[6,33]$. The Brønsted acid sites have also been shown to be active in and selective for the MeerweinPonndorf-Verley reduction [34,35]. Based on the above results, the 1-propanol formation mechanism catalyzed by $\mathrm{ZrNbO}$ catalysts can be proposed as follows (Scheme 2). A reaction mechanism for the conversion of 1,2-propanediol to propanal has already been proposed for zeolites [22]. We propose that the weak Brønsted acid sites act as sites for ligand exchange with the alcohol (1,2propanediol and some intermediates with hydroxyl groups) to form alkoxides on the catalyst. Propanal coordinates to the
Brønsted acid sites, activating the carbonyl group and initiating a hydride transfer from alcohol to the carbonyl. A ketone is formed and subsequent alcoholysis leads to the product, 1-propanol, and regeneration of the active catalyst.

\section{Conclusions}

In summary, a process for the conversion of 1,2-propanediol to 1-propanol over a ZrNbO catalyst was reported. A dehydration and hydrogen transfer mechanism was proposed. The $\mathrm{ZrNbO}$ species are active and selective catalysts for this reaction. The weak Brønsted acid sites may play a crucial role in the conversion of 1,2propanediol to 1-propanol.

\section{Acknowledgments}

This work was supported by the National Natural Science Foundation of China (Nos. 21273260, 21003146, 21201174 and 21303238), the Basic Research Project of the Qingdao Science and Technology Program (12-1-4-9-(6)-jch).

\section{References}

[1] M. Snare, I. Kubickova, P. Maeki-Arvela, D. Chichova, K. Eraenen, D.Y. Murzin, Fuel 87 (2008) 933.

[2] E. Van Ryneveld, A.S. Mahomed, P.S. Van Heerden, M.J. Green, H.B. Friedrich, Green Chem. 13 (2011) 1819.

[3] X.L. Wang, G.D. Wu, F. Wang, K.Q. Ding, F. Zhang, X.F. Liu, Y.B. Xue, Catal. Commun. 28 (2012) 73

[4] S. Hirasawa, Y. Nakagawa, K. Tomishige, Catal. Sci. Technol. 2 (2012) 1150.

[5] S. Hirasawa, H. Watanabe, T. Kizuka, Y. Nakagawa, K. Tomishige, J. Catal. 300 (2013) 205.

[6] P. Lauriol-Garbey, J.M.M. Millet, S. Loridant, V. Bellière-Baca, P. Rey, J. Catal. 281 (2011) 362.

[7] L.Q. Shen, H.B. Yin, A.L. Wang, X.F. Liu, C.H. Zhang, F. Chen, Y.T. Wang, H.J. Chen, J. Ind. Eng. Chem. (2013), http://dx.doi.org/10.1016//j.jiec.2013.06.004.

[8] Y. Kusunki, T. Miyazawa, K. Kunimori, K. Tomishige, Catal. Commun. 6 (2005) 645.

[9] Z.J. Wu, Y.Z. Mao, M. Song, X.Q. Yin, M.H. Zhang, Catal. Commun. 32 (2013) 52.

[10] Z.L. Yuan, P. Wu, J. Gao, X.Y. Lu, Z.Y. Hou, X.M. Zheng, Catal. Lett. 130 (2009) 261

[11] X.Y. Liao, K.W. Li, X.M. Xiang, S.Q. Wang, X.C. She, Y.L. Zhu, Y.W. Li, J. Ind. Eng. Chem. 18 (2012) 818.

[12] J.D. Unruh, D. Pearson, Kirk-Othmer Encyclopedia of Chemical Technology, John Wiley \& Sons, NY, 2000, 10.1002/0471238961.1618151621141821.a01.

[13] S.H. Zhu, Y.L. Zhu, S.L. Hao, H.Y. Zheng, T. Mo, Y.W. Li, Green Chem. 14 (2012) 2607.

[14] Y. Nakagawa, K. Tomishige, Catal. Sci. Technol. 1 (2011) 179.

[15] J. Guan, X.C. Wang, X.Y. Wang, X.D. Mu, Sci. China Chem. 56 (2013) 763.

[16] J. Guan, X.F. Chen, G.M. Peng, X.C. Wang, Q. Cao, Z.G. Lang, X.D. Mu, Chin. J. Catal. 34 (2013) 1656.

[17] M. Andreas, A. Udo, G. Inaki, L.A. Pedro, Eur. J. Lipid Sci. Technol. 115 (2013) 9.

[18] S. Koso, H. Watanabe, K. Okumura, Y. Nakagawa, K. Tomishige, Appl. Catal., B 111, 112 (2012) 27.

[19] Y. Nakagawa, X.H. Ning, Y. Amada, K. Tomishige, Appl. Catal. A 433, 434 (2012) 128.

[20] R. Arundhathi, T. Mizuqaki, T. Mitsudome, K. Jitsykawa, K. Kaneda, ChemSusChem 6 (2013) 1345.

[21] Y. Amada, S. Koso, Y. Nakagawa, K. Tomishige, ChemSusChem 3 (2010) 728

[22] D.Z. Zhang, S.A.I. Barri, D. Chadwick, Appl. Catal. A 400 (2011) 148.

[23] I. Gandarias, P.L. Arias, J. Requies, M. El Doukkali, M.B. Guemez, J. Catal. 282 (2011) 237.

[24] E. Arceo, P. Marsden, R.G. Bergman, J.A. Ellman, Chem. Commun. 23 (2009) 3357.

[25] G.K. Chuah, S. Jaenicke, S. Cheong, K. Chan, Appl. Catal., A 145 (1996) 267.

[26] K. Mori, Y. Yamada, S. Sato, Appl. Catal., A 366 (2009) 304.

[27] D.G. Barton, M. Shtein, R.D. Wilson, S.L. Soled, E. Iglesia, J. Phys. Chem. B 103 (1999) 630.

[28] I. Bucsi, A. Molnar, M. Bartok, Tetrahedron 50 (1994) 8159.

[29] S.H. Chai, H.P. Wang, Y. Liang, B.Q. Xu, Green Chem. 9 (2007) 1130.

[30] Y. Liu, H. Tüysüz, C. Jia, M. Schwickardi, R. Rinaldi, A. Lu, W. Schmidt, F. Schüth, Chem. Commun. 46 (2010) 1238.

[31] L.J. Burcham, J. Datka, I.E. Wachs, J. Phys. Chem. B 103 (1999) 6015.

[32] T. Onfroy, G. Clet, S.B. Bukallah, D.M. Hercules, M. Houalla, Catal. Lett. 89 (2003) 15.

[33] T. Onfroy, G. Clet, M. Houalla, J. Phys. Chem. B 109 (2005) 4588.

[34] S.H. Liu, S. Jaenicke, G.K. Chuah, J. Catal. 206 (2002) 321.

[35] F.J. Urbano, M.A. Aramendia, A. Marinas, J.M. Marinas, J. Catal. 268 (2009) 79. 